\title{
A method of thermal error prediction modeling for CNC machine tool spindle system
}

Wenjie Cao ( $1127795792 @ q q . c o m)$

University of Shanghai for Science and Technology

Haolin Li

Qiang Li

\section{Research Article}

Keywords: Spindle system, Thermal error, Error modeling, Linear correlation, MI, PCA, MR

Posted Date: April 19th, 2021

DOI: https://doi.org/10.21203/rs.3.rs-416864/v1

License: (a) (1) This work is licensed under a Creative Commons Attribution 4.0 International License. Read Full License 


\section{Abstract}

In order to improve the machining accuracy of the thermal error prediction model of CNC machine tools, a new method for calculating the position of the measuring points optimal combination researched on linear correlation is proposed, according to the thermal-mechanical finite element analysis(FEA) model of spindle system established after analyzing the thermal characteristics of heat source temperature field of CNC machine tool spindle system. Based on the correlation analysis(CA) of the finite element model of heat source temperature field of CNC machine tool spindle system, combined with the concept of mutual information (MI), this method measures the information of the measurement point variables including the thermal error variables and uses principal component analysis (PCA) to eliminate the collinearity effect within measuring point variables. By using multilinear regression(MR), The thermal error prediction model(CAMI-PCAMR) is established. The accuracy of the prediction model is verified by comparing the actual measurement thermal error with the predicted thermal error through the experimental measurement and analysis of the thermal error of the CNC end grinder test machine tool system. That the axial prediction accuracy of this method can reach $1.099 \mu \mathrm{m}$, and the prediction radial accuracy can reach $1.28 \mu \mathrm{m}$ under the variable ambient condition, so as to provide parameters and theoretical guidance for embedding temperature sensors in the machine tool to compensate thermal error in the design stage. And the experimental results also show that the CAMI-PCAMR method is superior to the gray correlation and fuzzy clustering(FC-GCA) modeling method.

\section{Full Text}

This preprint is available for download as a PDF.

\section{Figures}




\section{Temperature}

Type: Temperature

Unit: ${ }^{\circ} \mathrm{C}$

Time: 28800

2020/12/31 9:15

\subsection{Max}

40.739

38.273

35.807

33.341

30.874

28.408

25.942

23.476

21.009 Min
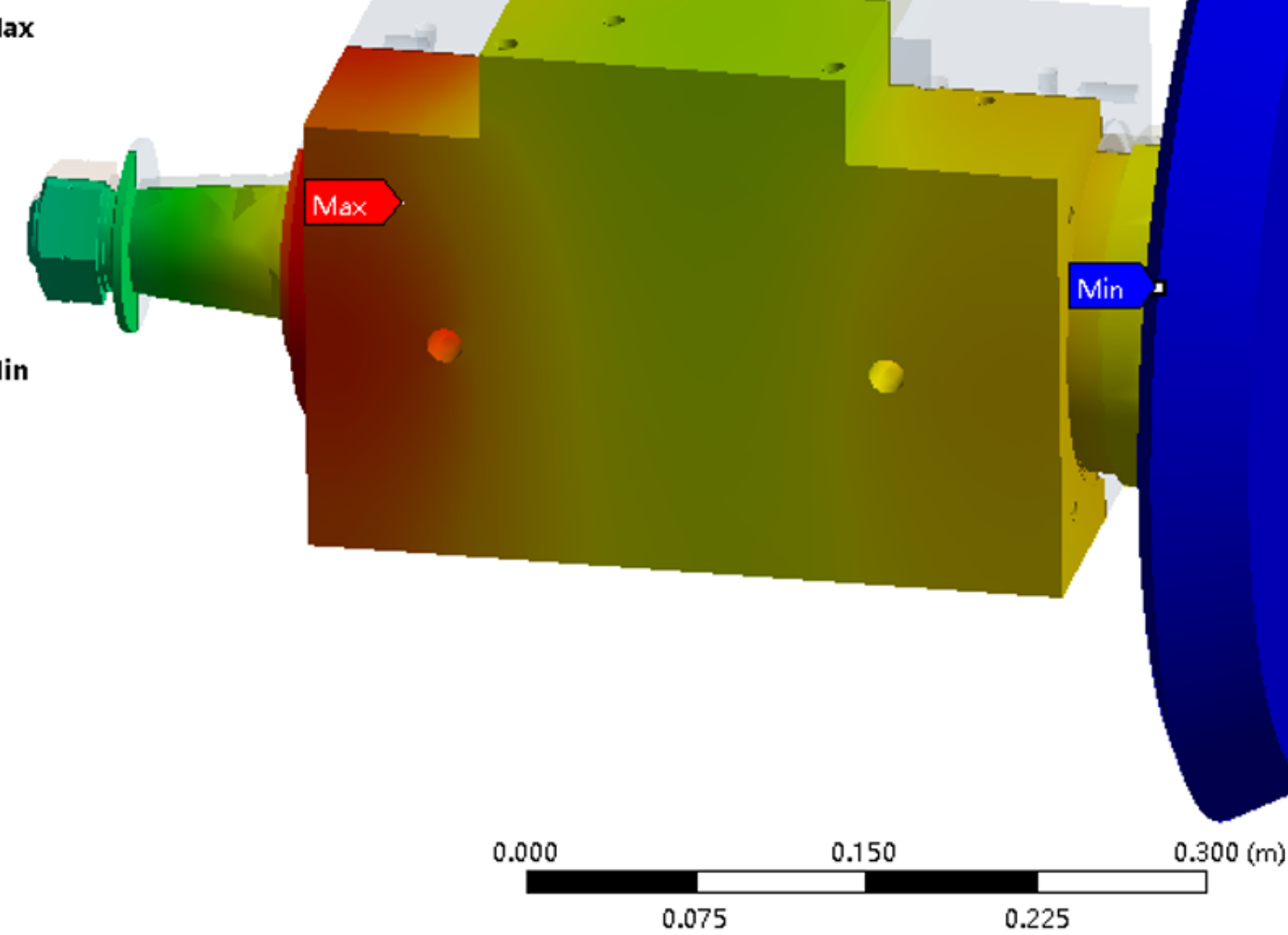

\section{Figure 1}

Temperature field distribution of spindle system

C: Transient Structural

Type: Directional Deformation $(\times$ Axis $)$

Type: Direct
Unit: $\mu \mathrm{m}$

Global Coordinate System

Time: 28800

2020/12/31 11:53
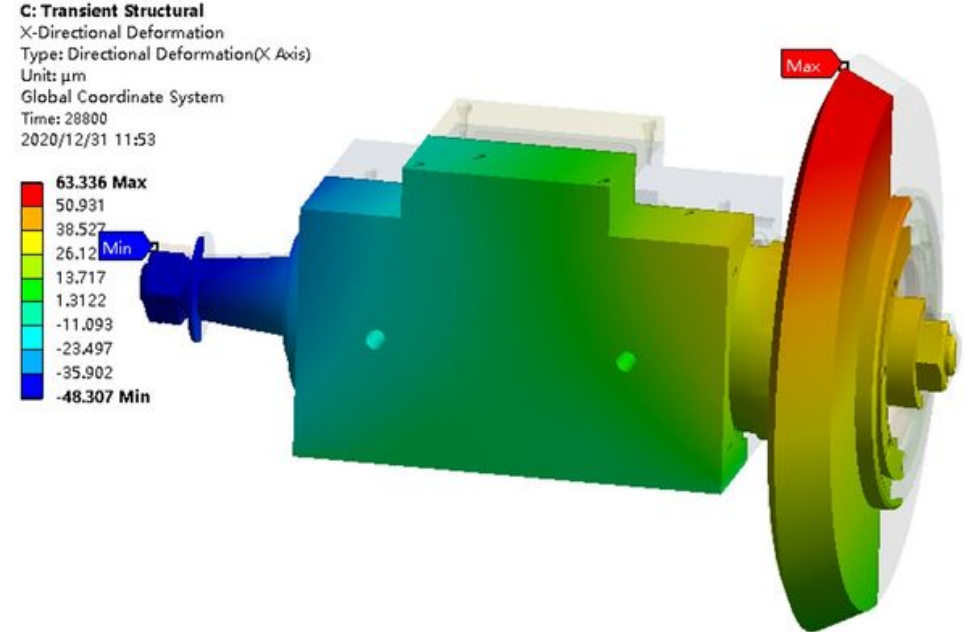

C: Transient Structural

Z-Directional Deformation

Type: Direct

Global Coordinate System

Time: 28800

$2020 / 12 / 3111: 52$

$61.04 \mathrm{Max}$

53.882

53.882
46.723

39.565

32.407
25.249

25.249
18.09

18.09
10.932

3.7739

$.3 .3844 \mathrm{Min}$

48.307 Min
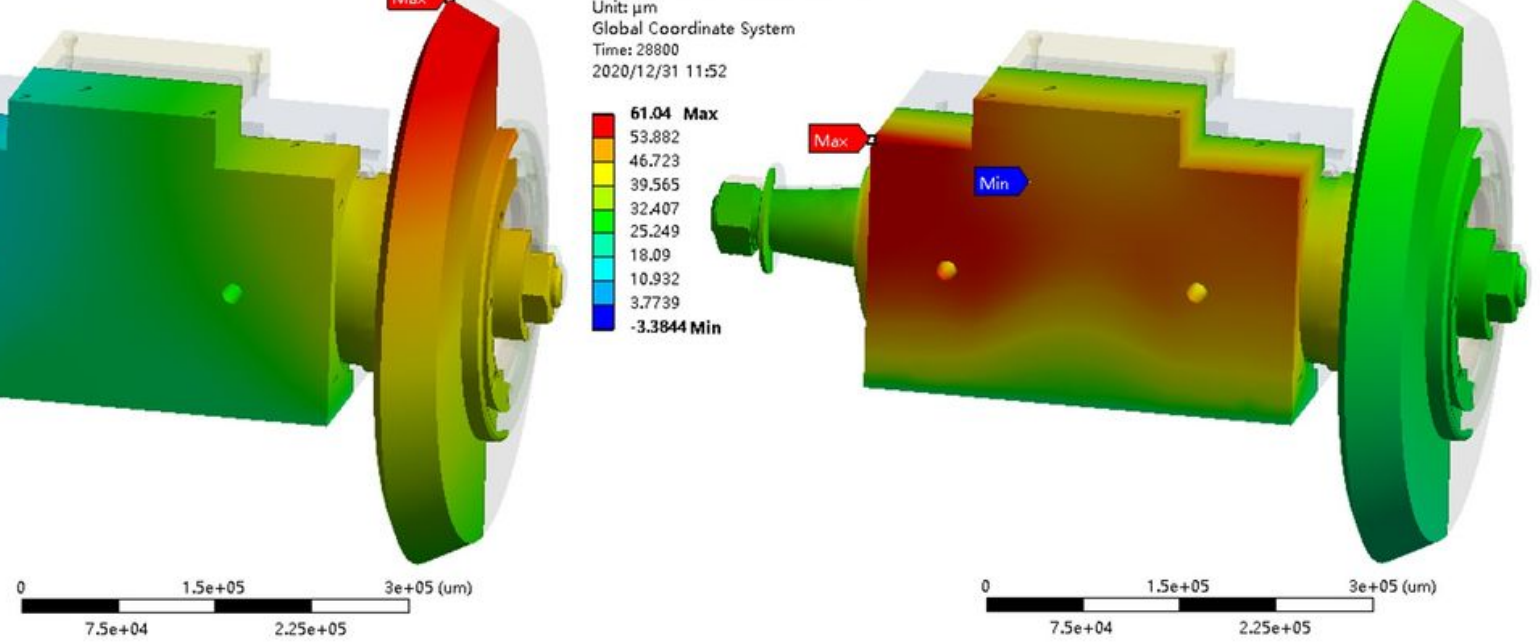

Figure 2 
(a) Axial thermal error nephogram of spindle (b) Radial thermal error nephogram of spindle. Thermal error distribution of spindle system

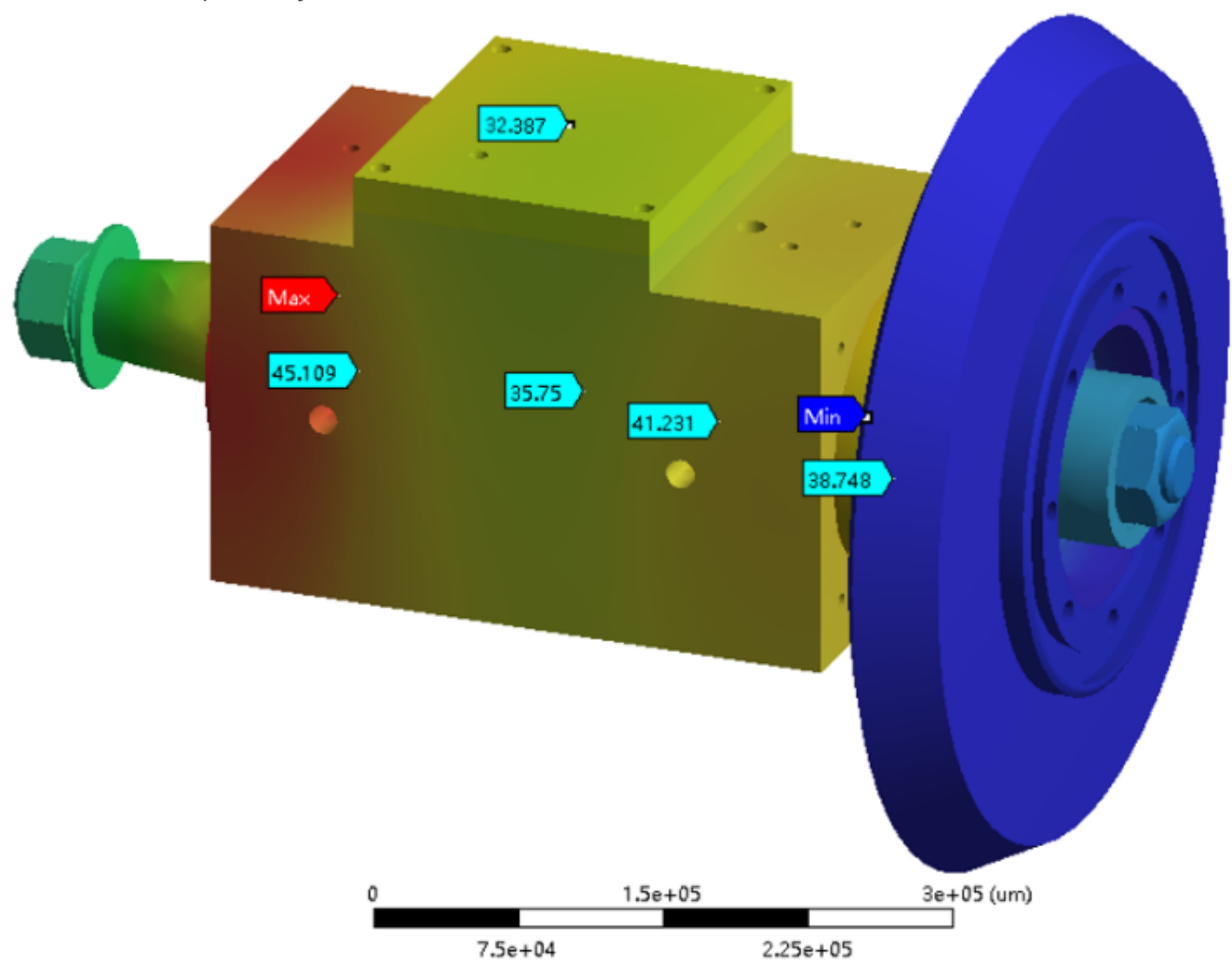

Figure 3

Schematic diagram of machine tool spindle node position 


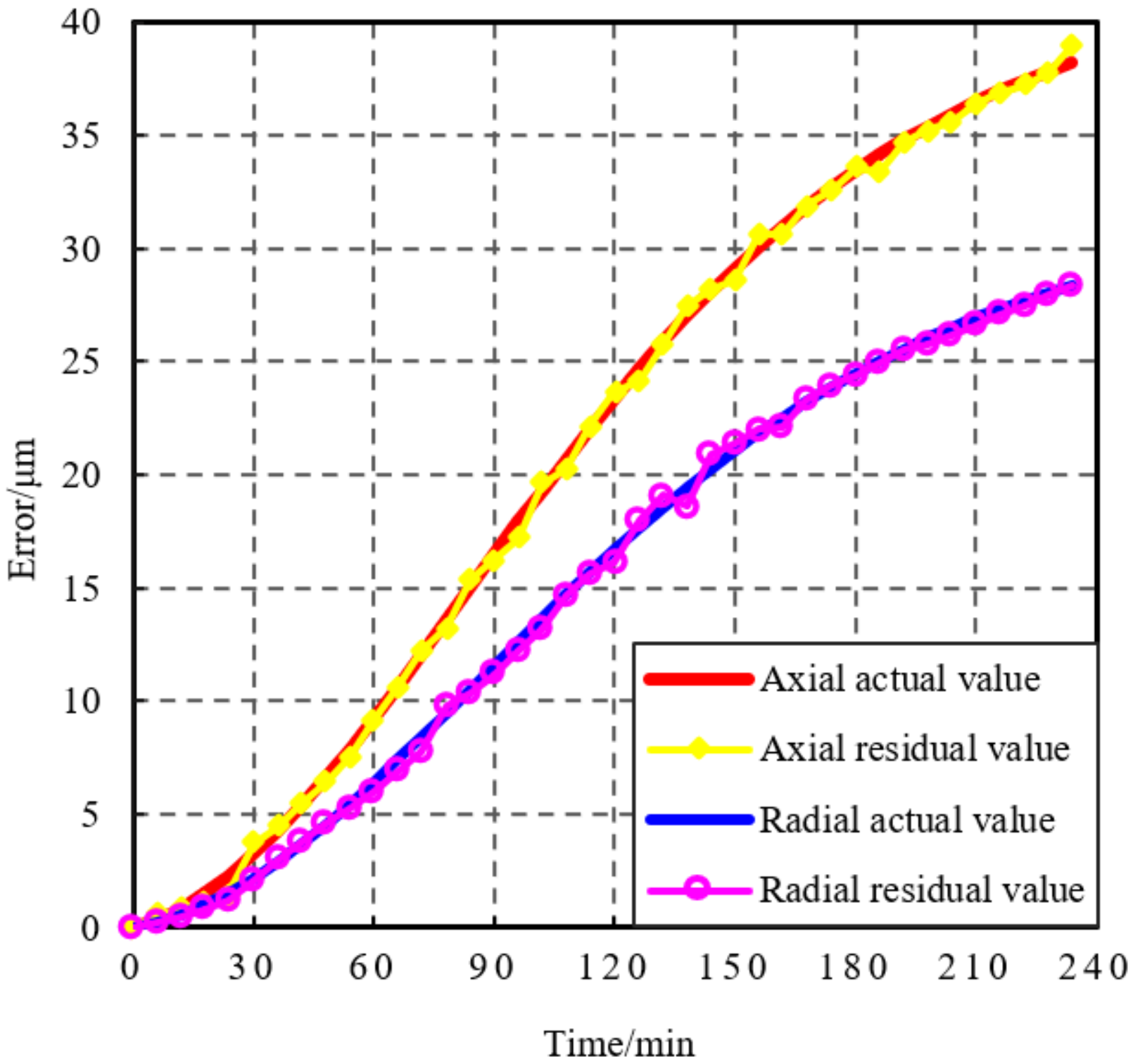

Figure 4

The comparison of axial and radial thermal deformation E_1,E_2 and actual value 


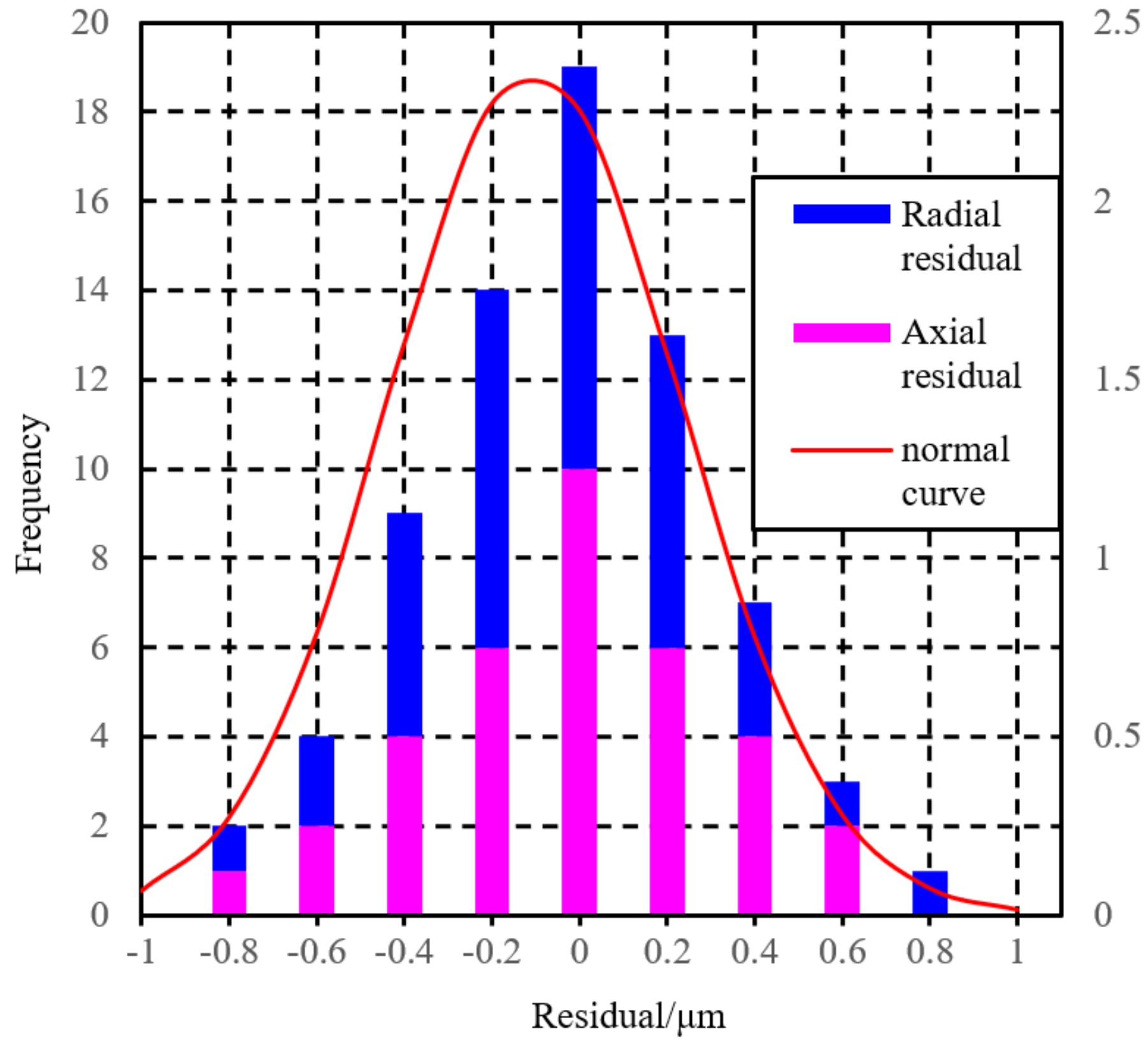

Figure 5

The normal distribution of residual error of axial and the radial thermal deformation prediction model 


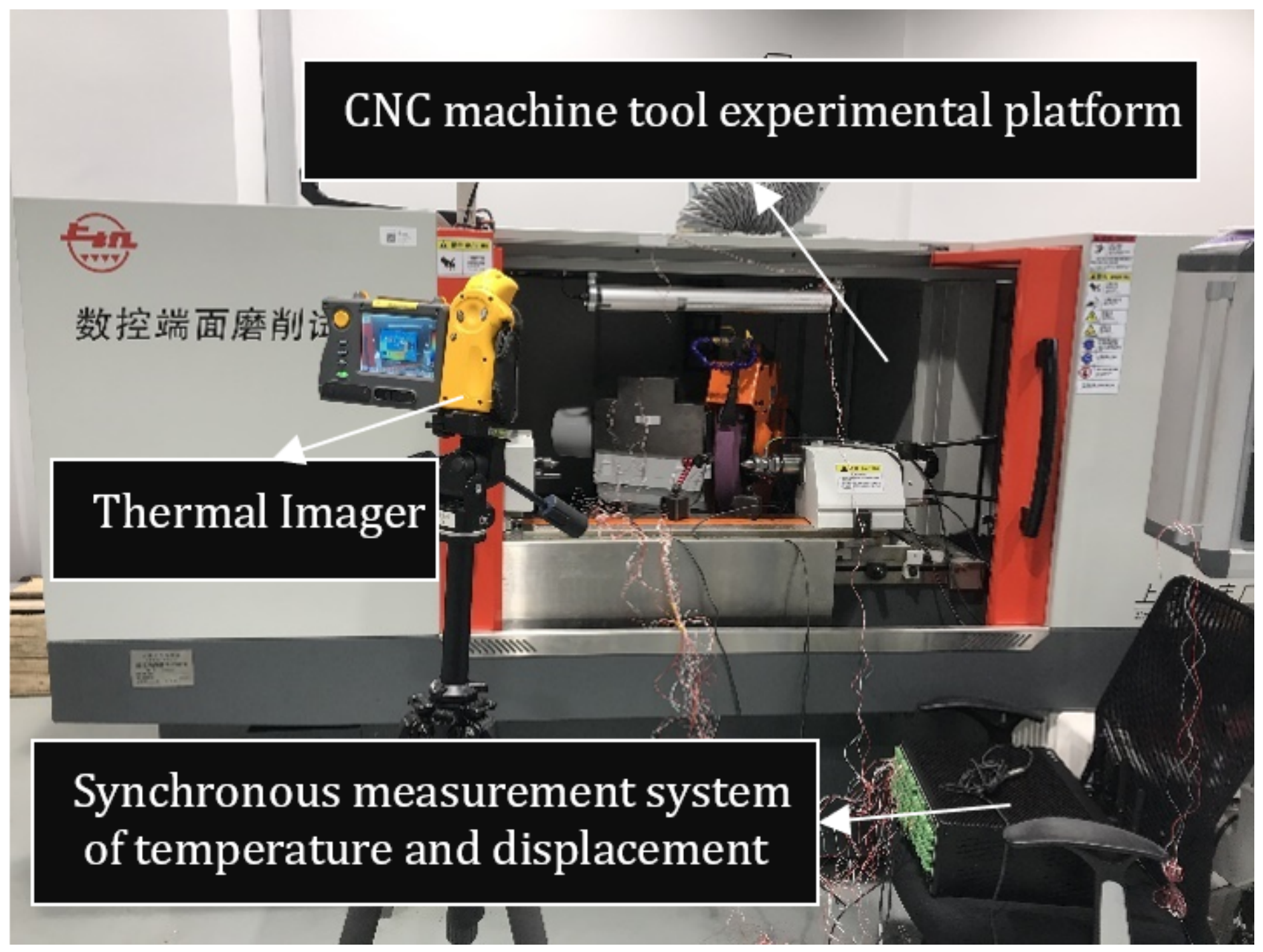

Figure 6

The experimental platform of actual CNC grinder 


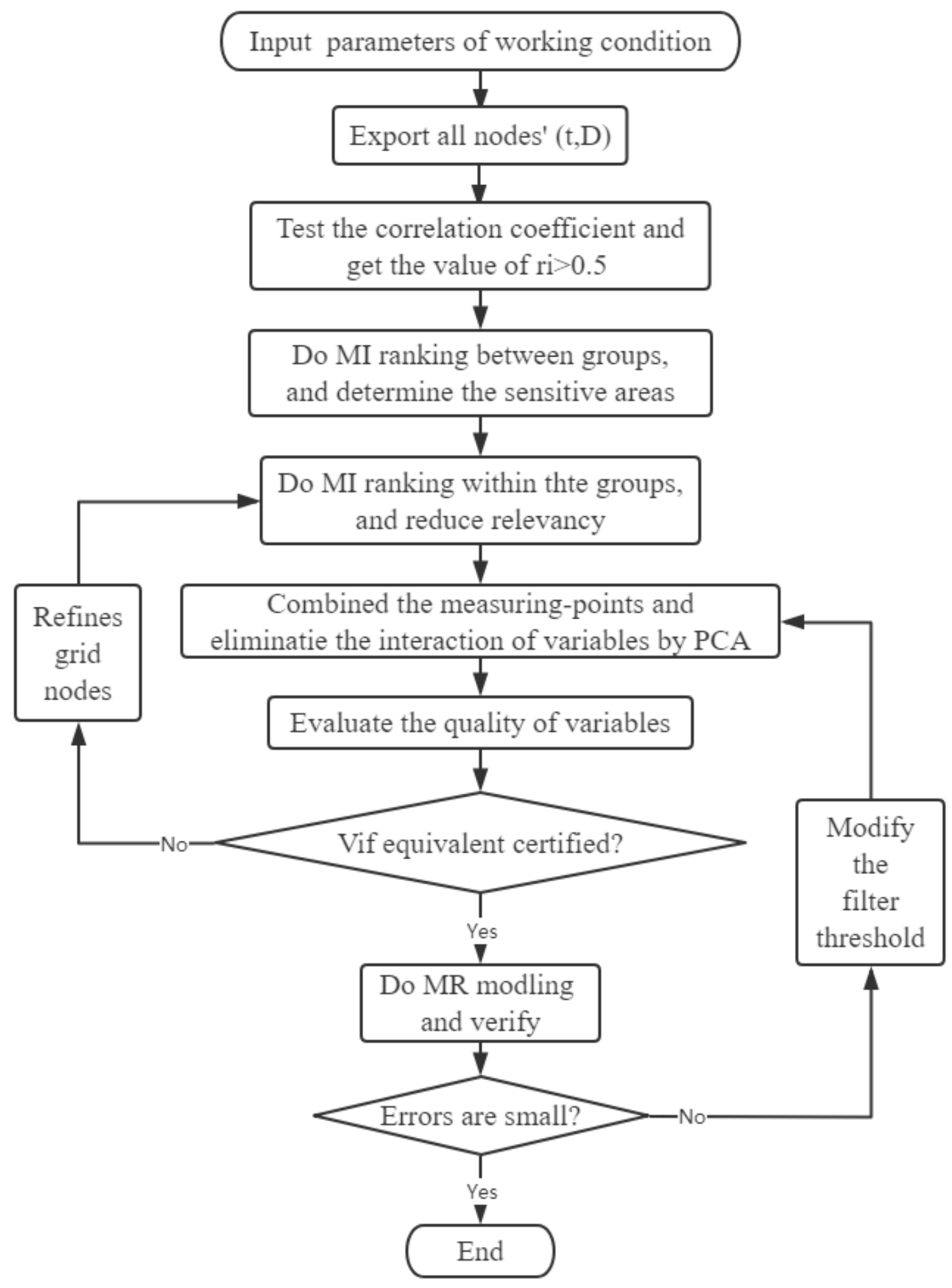

Figure 7

The flow chart of CAMI-PCAMR modeling method 


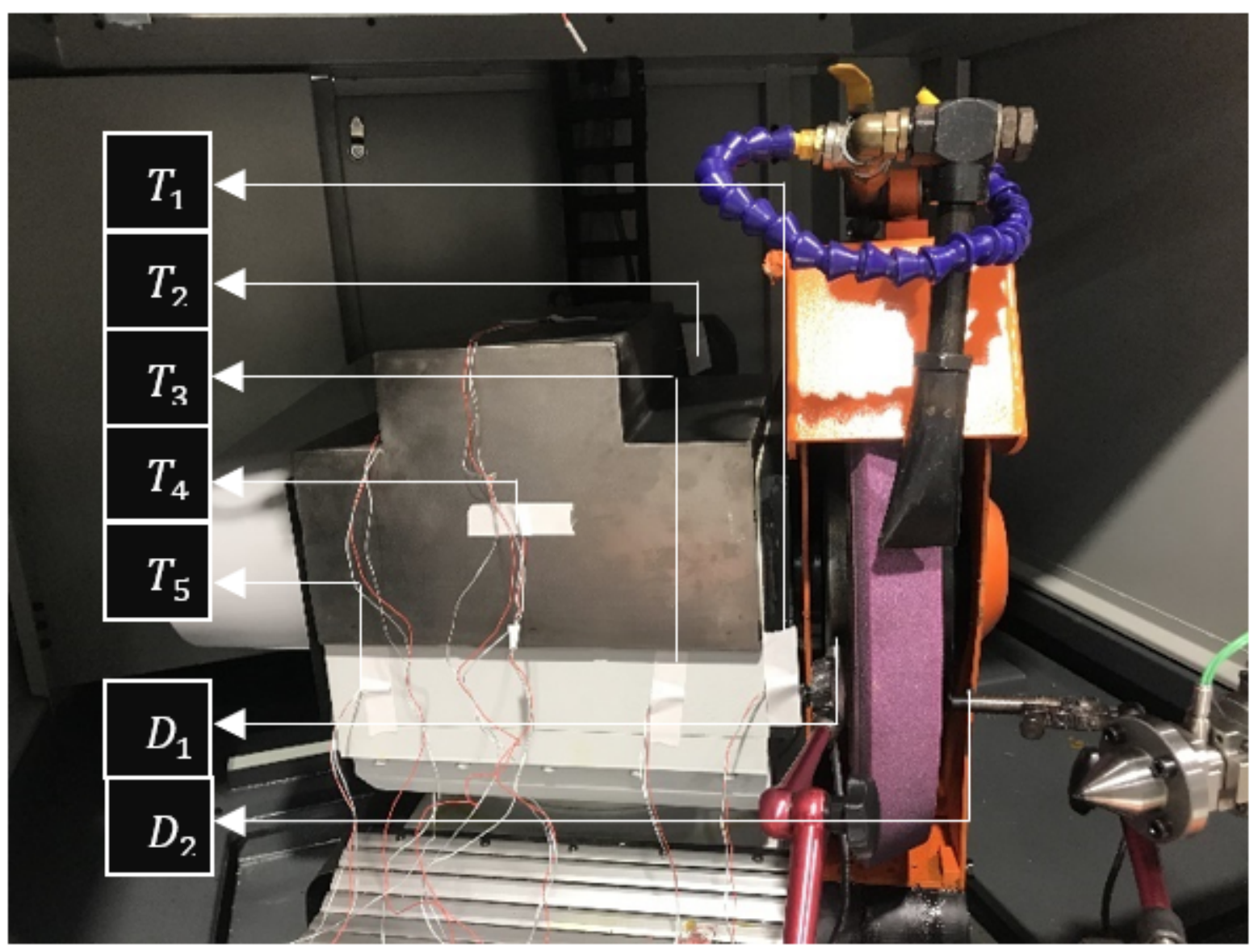

Figure 8

The layout of sensors 


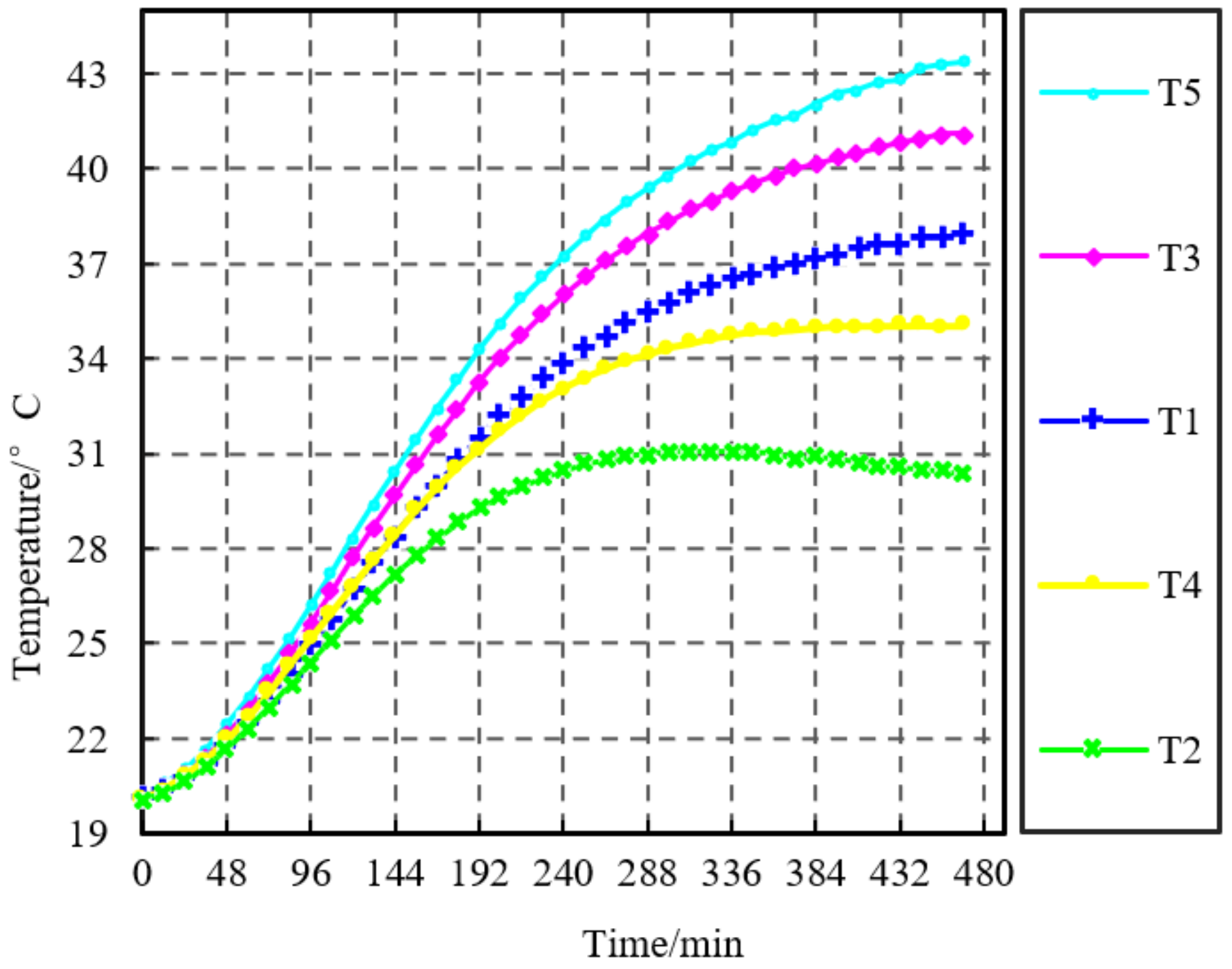

Figure 9

The temperature measurement points of experimental platform 

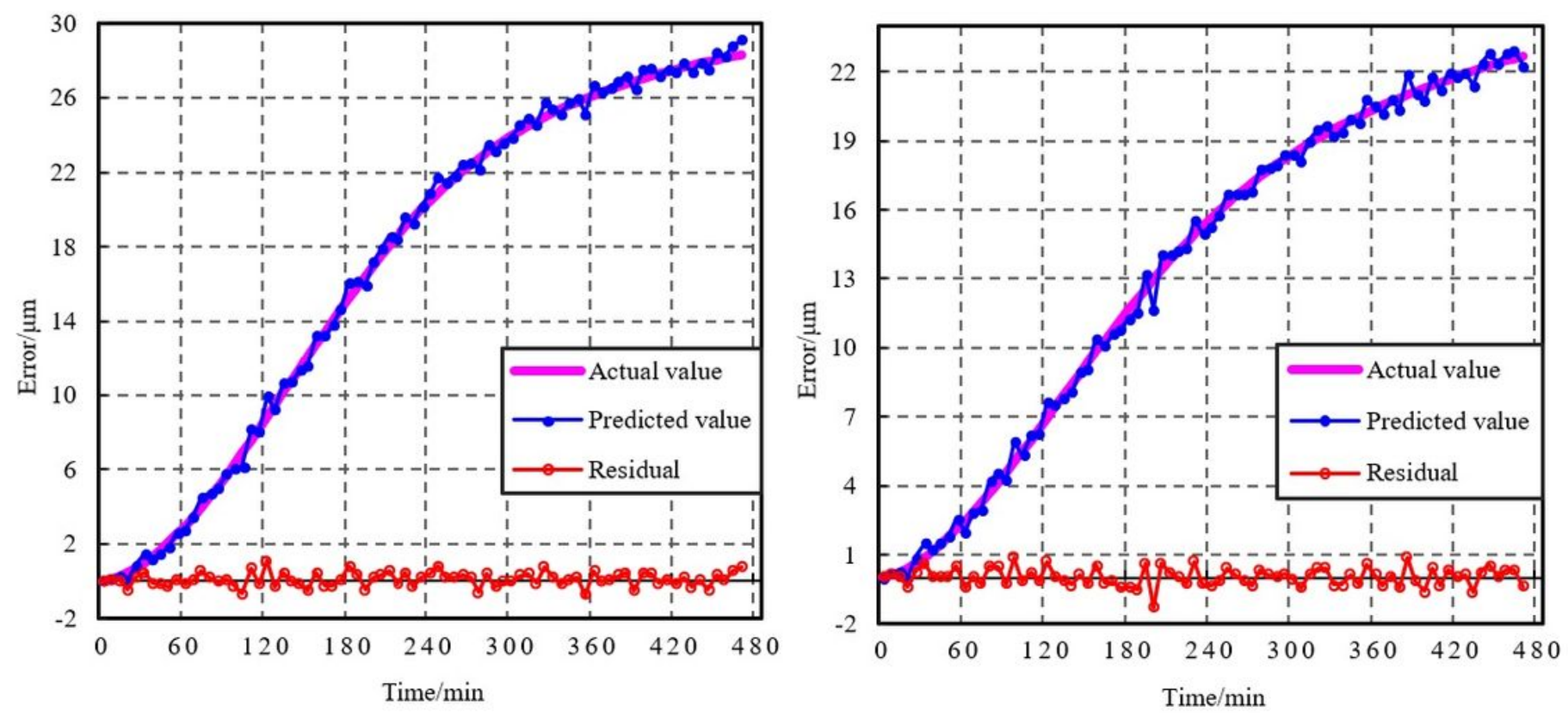

Figure 10

The results of CAMI-PCA MLR prediction model. (a) Result of the axial thermal error model (b) Result of the radial thermal error model 


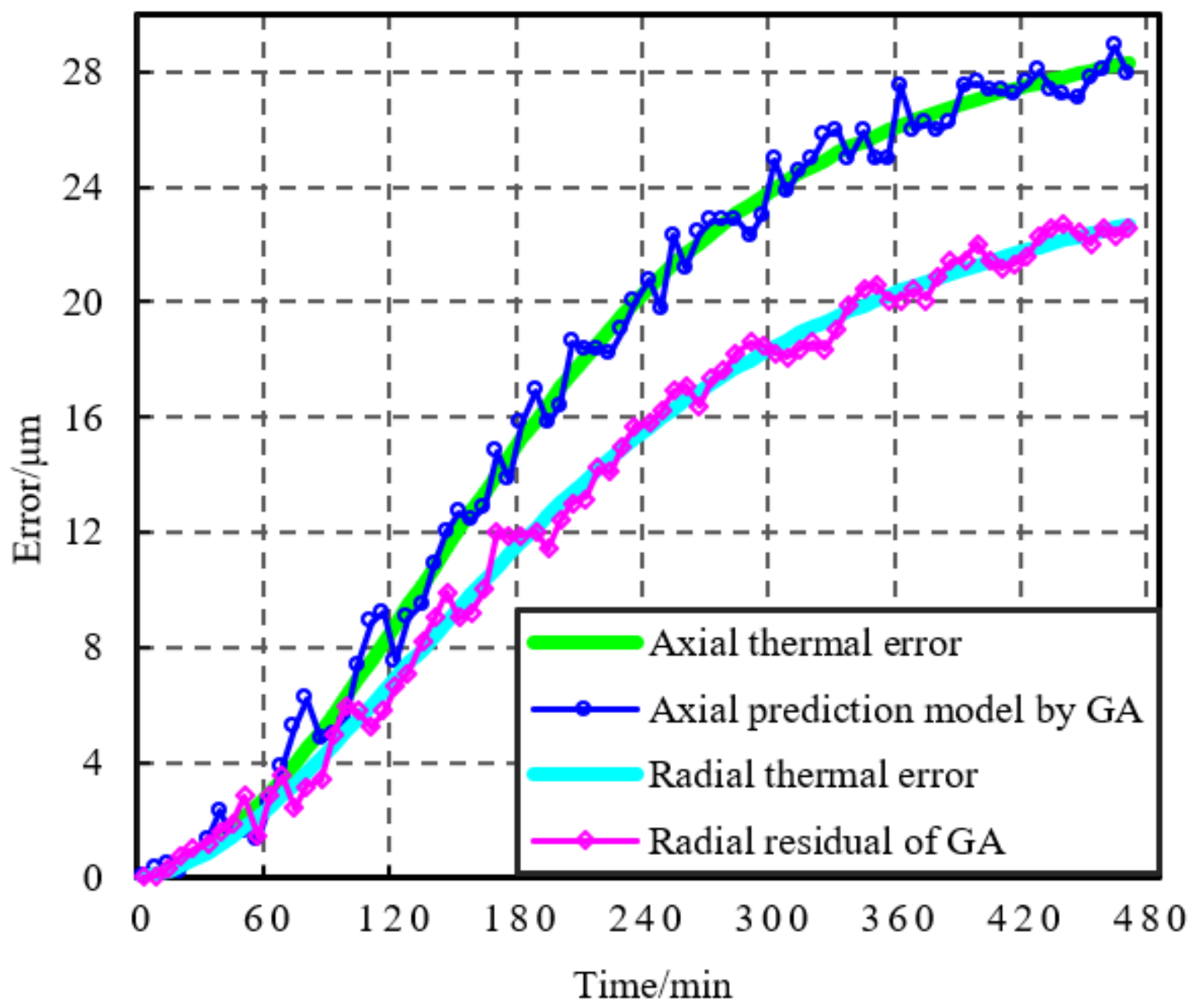

Figure 11

The prediction results of GA model 


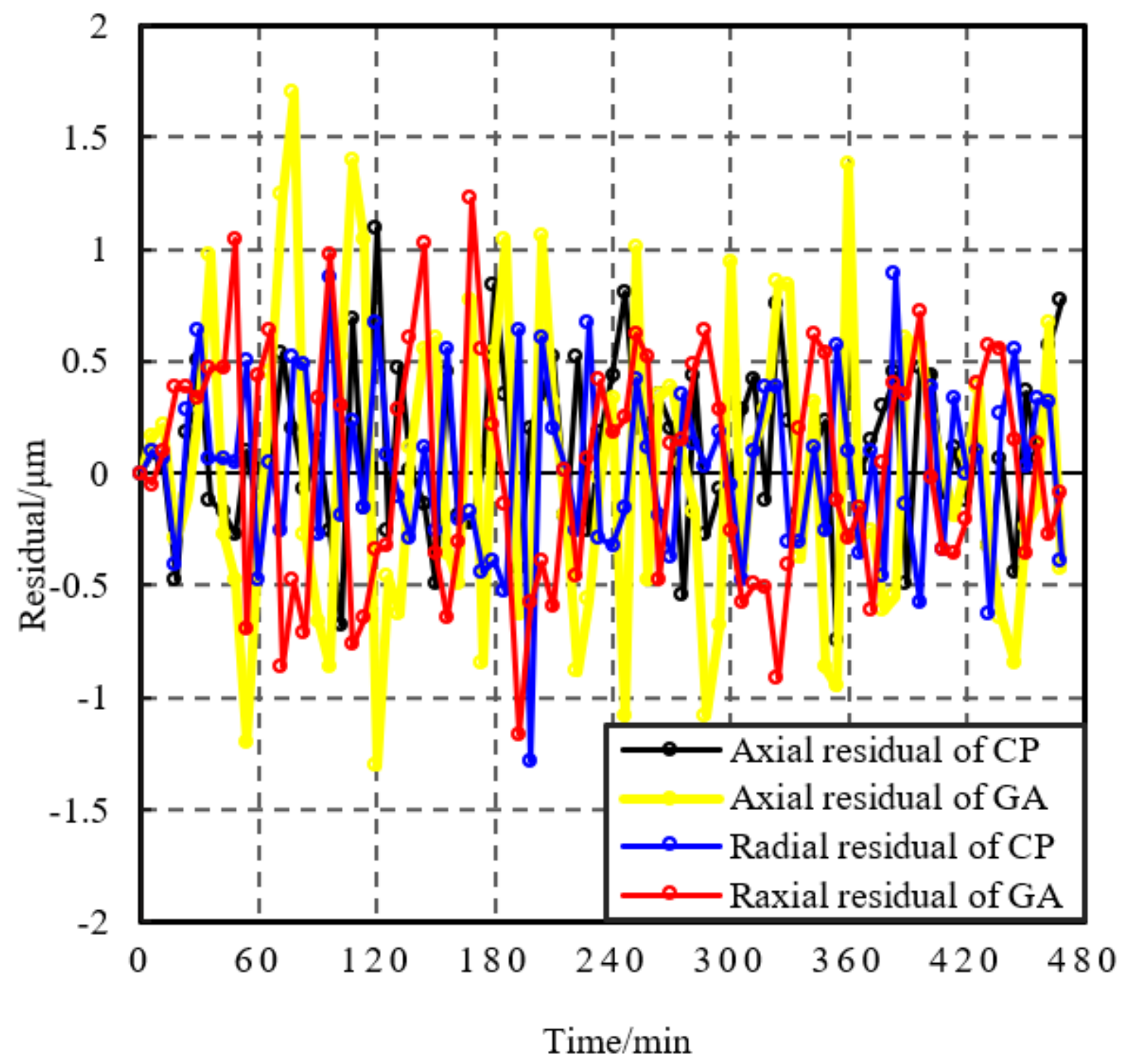

Figure 12

The comparison of prediction model residuals 